\title{
A Middle-Aged Female with Multiple Brownish Plaques and Nodules: A Case Report of Multiple Cutaneous Reticulohistiocytomas
}

\author{
Sijapati KS ${ }^{1}$, Agrawal $\mathbf{S}^{2}$, Karki $\mathbf{S}^{3}$ \\ ${ }^{1}$ Senior Resident; ${ }^{2}$ Professor, Department of Dermatology \& Venereology; ${ }^{3}$ Professor, Department of Pathology, B.P \\ Koirala Institute of Health Sciences, Dharan, Nepal.
}

\begin{abstract}
Non-Langerhans-Cell histiocytosis spectrum of disorders includes multicentric reticulohistiocytosis (MR) and multiple cutaneous reticulohistiocytomas (MCR), which are very uncommon granulomatous conditions. In reticulohistiocytoma, the most common sites of involvement are extensor surfaces, particularly the hands and forearms and the classical lesions are characterised by firm brown or yellow papules, nodules and plaques. As MCR is a very rare granulomatous condition, we report here a middle-aged female a case of MCR and we highlight the significance of considering reticulohistiocytoma in the differential diagnoses of chronic and persistent brownish plaques or nodules on skin.

Key words: Azathioprine; cyclophosphamide; histiocytes; histiocytosis, non-langerhans-cell
\end{abstract}

\section{Introduction}

$\mathrm{N}$ on-Langerhans-Cell histiocytosis spectrum of disorders include multicentric reticulohistiocytosis (MR) and multiple cutaneous reticulohistiocytomas (MCR), which are very uncommon granulomatous conditions. In reticulohistiocytoma, the most common site of involvement are extensor surfaces, particularly the hands and forearms and the classical lesions are characterised by firm brown or yellow papules, nodules and plaques. ${ }^{1}$ In MR, skin lesions occur in association with a severe, destructive, arthropathy, mucosal involvement and other systemic features. MCR cutaneous lesions are histologically identical to $M R$, developing in the absence of arthritis or other systemic lesions. ${ }^{2}$ As MCR is a very rare granulomatous condition, we report here a middle-aged female a case of MCR and we highlight the significance of considering reticulohistiocytoma in the differential diagnoses of persistent and chronic brownish plaques or nodules on skin.

\section{Case report}

A 30-year-old female presented in Dermatology OPD with the appearance of multiple brownish coloured

\author{
Address of Correspondence: \\ Dr. Karuna Singh Sijapati \\ Department of Dermatology \& Venereology \\ B.P. Koirala Institute of Health Sciences, Dharan, Nepal \\ E-mail:mokshya736@gmail.com
}

pea sized raised skin lesions over extensor aspects of bilateral (b/l) upper and lower limbs associated with itching for 3 years. No history of ( $h / o$ ) anorexia, weight loss, weakness, pallor, joint pain, tingling sensation, yellowish discoloration of sclera, shortness of breath, chest pain, epigastric pain, fever, atopy, no personal and family history of tuberculosis. Cutaneous examination showed the presence of multiple brownish coloured papules, nodules and plaques over extensor aspects of bilateral upper and lower limb measuring around $0.3 \mathrm{~cm} \times 0.3 \mathrm{~cm}, 0.8 \mathrm{~cm} \times 0.8 \mathrm{~cm}$ and plaques measuring smallest of $1.5 \mathrm{~cm} \times 0.8 \mathrm{~cm}$ to largest of $3 \mathrm{~cm} \times 2 \mathrm{~cm}$ respectively (Figure 1 ). All mucosae, hair and nails were normal.

\footnotetext{
Submitted: $2^{\text {nd }}$ January 2018

Accepted: $15^{\text {th }}$ February 2018

Published: $21^{\text {st }}$ March 2018
}

\section{How to cite this article}

Sijapati KS, Agrawal S, Karki S. A middle-aged female with multiple brownish plaques and nodules: $A$ case report of multiple cutaneous reticulohistiocytomas. Nepal Journal of Dermatology Venereology and Leprology. 2018;16(1):63-5. doi: http://dx.doi.org/10.3126/njdvl.v16i1.19417

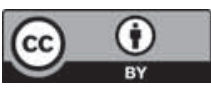

Licensed under CC BY 4.0 International License which permits use, distribution and reproduction in any medium, provided the original work is properly cited. 
On laboratory investigations - Complete blood count, peripheral blood smear, absolute eosinophil count, liver function test, renal function test and chest $\mathrm{x}$-ray were normal. While deranged parameters were ESR-34 $\mathrm{mm} /$ hour, Cholesterol-239 $\mathrm{mg} / \mathrm{dl}$ and X-ray bilateral hand showed diffuse osteopenia in the distal end of radius, ulna, carpal bones, and juxta-articular region of metacarpal and phalanges but no sclerotic and lytic lesions were seen. Histopathological examination showed vaguely nodular collection of mononuclear histiocytes with plump nucleus and moderate amount of eosinophilic cytoplasm. Foci of foamy, macrophages, intermingled multi-nucleated giant cells some of touton type with proliferation of fibroblasts and inflammatory cells such as lymphocytes and occasional neutrophils. Lesional biopsy was histologically suggestive of reticulohistiocytoma (Figure 2). Therapy with oral hydroxychloroquine, tapering dose of oral prednisolone (over a period of 6weeks) and topical tacrolimus $0.1 \%$ resulted in complete clearance by 20 weeks leaving behind mild post-inflammatory hyperpigmentation (Figure $3 a, b$ and $4 a, b$ ).
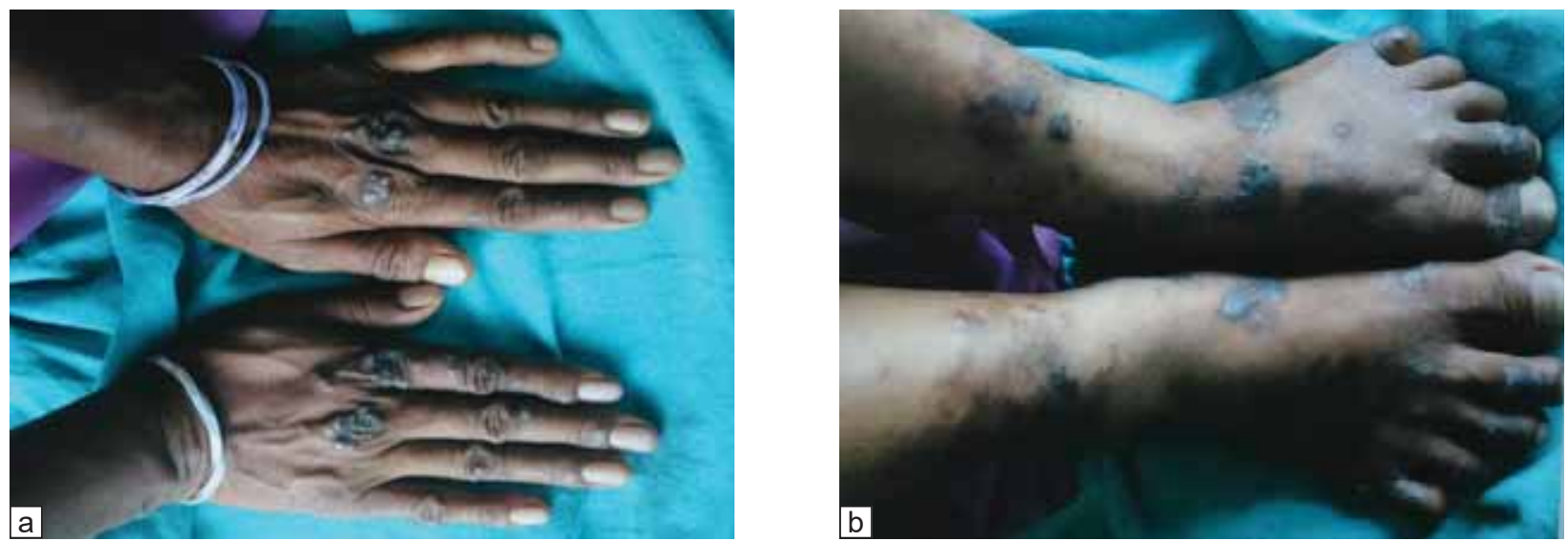

Figure 1: Multiple brownish coloured papules, nodules and plaques over dorsum of bilateral hands (a) and feet (b).
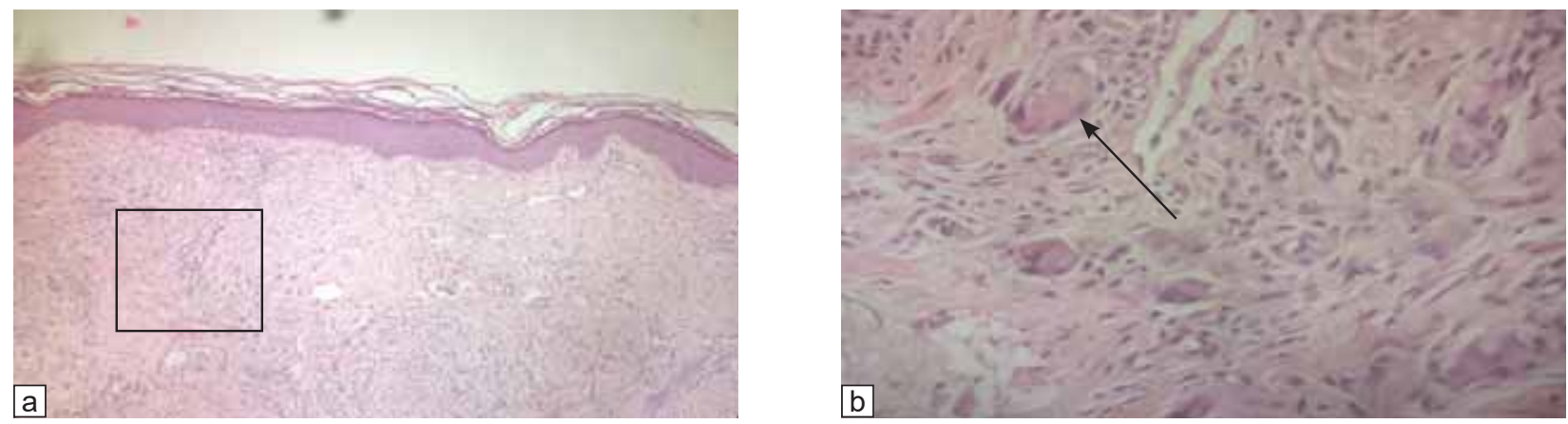

Figure 2: Histopathological examination: a) Orthokeratosis, thinning of epidermis and diffuse inflammatory infiltrate in dermis $(4 \times 1)$. b) Mononuclear histiocytes with plump nucleus and moderate amount of eosinophilic cytoplasm and intermingled multi-nucleate giant cells (black arrow) $(40 \times 1)$.
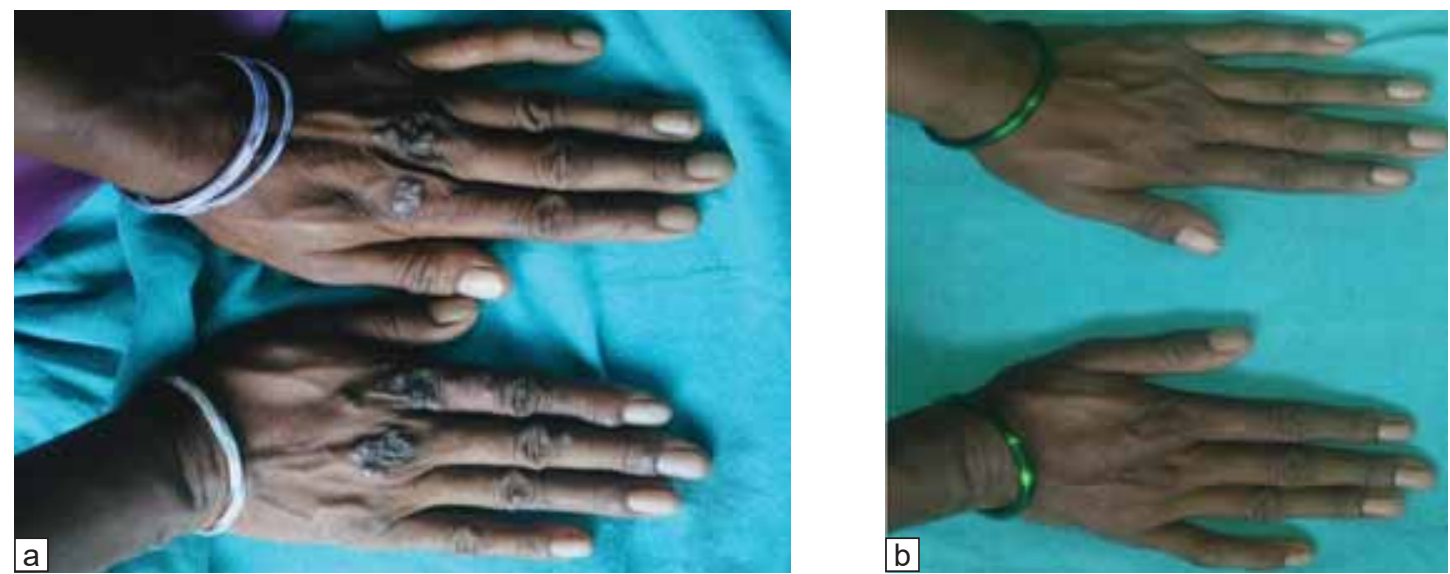

Figure 3: a) Baseline b) After 20 weeks of treatment. 


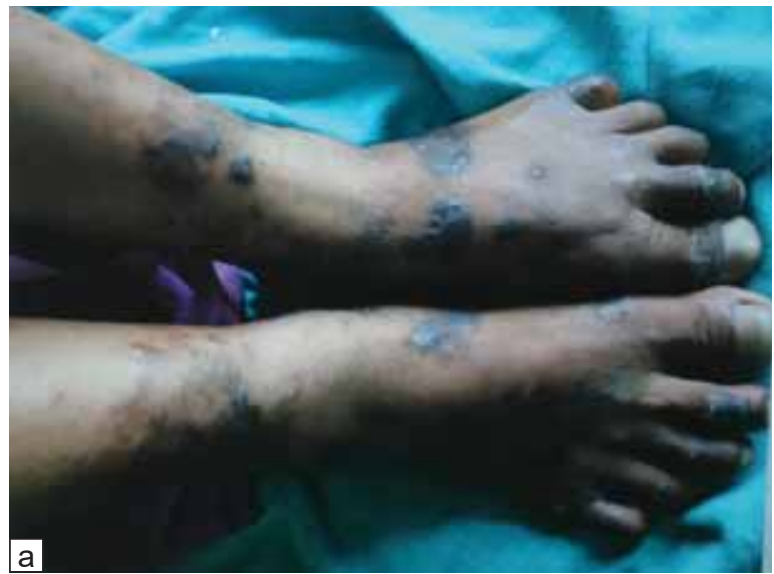

Figure 4: a) Baseline b) After 20 weeks of treatment.

\section{Disaussion}

MCR is characterized by proliferation and differentiation of an anomalous histiocytic clone in response to unknown stimuli. ${ }^{3}$ Although the exact pathogenesis is not known but the disease has been regarded as a reactive histiocytosis. In MCR infective causative agents have no role, however it is associated with exposure to tuberculosis. This can be evidenced by a study in which, of the total patients with MCR, $33 \%$ had exposure to tuberculosis, $5 \%$ had active tuberculosis and $20 \%$ had malignancy. ${ }^{4}$ No any genetic associations has been found. ${ }^{1}$

MCR is rarely reported in the literature. . $^{3,5,6}$ Histopathology of reticulohistiocytoma shows numerous multinucleated giant cells and oncocytic macrophages showing abundant eosinophilic, finely granular cytoplasm with ground glass appearance. ${ }^{4}$ Histology with immunocytochemistry usually confirms the diagnosis of MCR. Staining with Vimentin and CD45

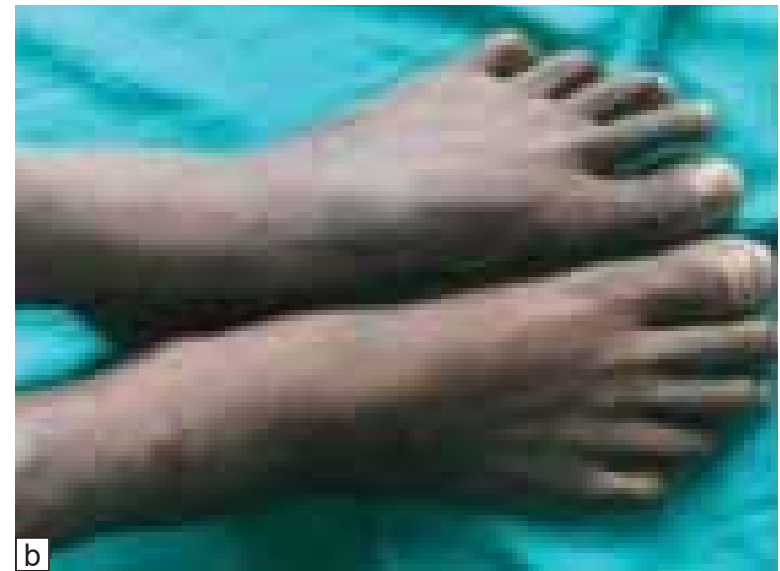

are positive but FXIIla is negative. ${ }^{4}$ Other diseases that necessitate to be differentiated include sarcoidosis, xanthoma, mastocytosis, leprosy and lymphoma.

Systemic steroid with azathioprine or other immunosuppressive drug (cyclophosphamide, ciclosporin) usually improves the condition. ${ }^{5}$ Pulsed dye laser, oral corticosteroids, and methotrexate has been tried in the treatment of extensive lesions. ${ }^{6}$

\section{Condusion}

Although reticulohistiocytoma is an extremely rare granulomatous condition. One should consider reticulohistiocytoma in the differential diagnoses of persistent brownish plaques or nodules on the skin in any middle-aged female.

Financial disclosure: None.

Conflicts of interest to disclosure: None declared.

4. Burgdorf HCW and Zelger B. The Histiocytoses. In: Elder ED, Elenitsas R, Johnson LB, Murphy FG, $\mathrm{Xu}$ X. (eds). Lever's Histopathology of the Skin. $10^{\text {th }}$ ed. Philadelphia: Wolters Kluwer/Lippincott Williams \& Williams; 2009. p.675-6.

5. Ghosh SK, Bandyopadhyay D, Ghosh A, Bar C. Multiple yellowish plaques and nodules in a young man. A case of multiple cutaneous reticulohistiocytomas. J Turk Acad Dermatol. 2009;3:93202c.

6. Bansal M, Manchanda K, Pandey SS. Multiple cutaneous reticulohistiocytoma in middle aged female. Indian Dermatol Online J. 2014;5(1):746. https://doi.org/10.4103/2229-5178.126040 